(1)

CrossMark

\title{
Asthma attacks: should we nail our colours to the mast (cell)?
}

\author{
Louise Fleming ${ }^{1,2}$, Sejal Saglani ${ }^{1,2}$ and Andrew Bush ${ }^{1,2}$
}

Affiliations: ${ }^{1}$ Paediatric Respiratory Medicine, NHLI Imperial College London, London, UK. ${ }^{2}$ Dept of Paediatric Respiratory Medicine, Royal Brompton Hospital, Royal Brompton Harefield NHS Foundation Trust, London, UK.

Correspondence: Andrew Bush, Dept of Paediatric Respiratory Medicine, Royal Brompton Hospital, Sydney Street, London, SW3 6NP, UK. E-mail: a.bush@imperial.ac.uk

@ERSpublications

Why do only some asthmatic children exacerbate, what is the underlying pathology, and how should we treat them? http://ow.ly/Mrik304eIVU

Many common airway diseases are characterised by chronic symptoms with interspersed acute and unpredictable deteriorations, conventionally called "pulmonary exacerbations". Until relatively recently, these so-called exacerbations were a rather Cinderella subject, relatively neglected in favour of treating day-to-day problems. This may in part be because in asthma, for example, we have treatments such as inhaled corticosteroids (ICS) which are enormously effective in treating chronic symptoms, but prevention of exacerbations is much less successful. However, it is becoming increasingly clear that pulmonary exacerbations carry much more sinister overtones than once we thought, to the extent that the term "lung attacks" has been proposed to describe them [1,2]. In cystic fibrosis (CF), treatment of lung attacks even with intravenous antibiotics may fail to restore spirometry to baseline [3], and are associated with an accelerated decline in lung function [4] and a worse prognosis [5]. Failure of response is also described in primary ciliary dyskinesia [6]. Lung attacks, as we shall continue to describe them, have been used as clinical trial end-points in CF [7] and bronchiectasis [8], and may be a more sensitive marker of response than spirometry [9]. They are very far from being a minor and reversible inconvenience to the patient with airways disease.

Exacerbations of asthma cause considerable morbidity and mortality; and, as recently confirmed yet again by the UK National Review of Asthma Deaths (NRAD) [10], a previous acute attack is a very strong predictor of asthma death. It has long been known that, physiologically, loss of asthma control and asthma attacks are different phenomena [11]. Furthermore, asthma attacks are predictive both of failure of normal airway growth [12], and an accelerated rate of decline of spirometry [13]. It is thus very clear that understanding why patients have asthma attacks, and preventing them, is a high priority. It is also abundantly clear that our definitions of "severe" asthma are woefully inadequate, a point to which we return; nearly $70 \%$ of asthma deaths were in people who did not have "severe" asthma [10], despite most people believing that asthma death is a pretty bad outcome!

However, seemingly paradoxically, only a subset of asthmatics appear to exacerbate [14], and this is certainly an area in which risk stratification is needed. Reasons for asthma attacks may be considered as behavioural and biological, and so prevention needs a multifaceted approach. On the behavioural side, failure to attend follow-up appointments, overuse of short-acting $\beta 2$-agonists and underuse of ICS are among the most important factors [10]. Biologically, the combination of viral infection, allergen sensitisation and high environmental allergen exposure are strongly predictive of attacks needing hospitalisation [15]. Adult data, in particular, have highlighted that asthma can apparently be perfectly controlled despite ongoing underlying eosinophilic airway inflammation, but that such patients are at high

Received: Aug 122016 | Accepted: Aug 162016

Support statement: A. Bush is an NIHR Senior Investigator, and was additionally supported by the NIHR Respiratory Disease Biomedical Research Unit at the Royal Brompton and Harefield NHS Foundation Trust and Imperial College London. S. Saglani is an NIHR Career Development Fellow. Funding information for this article has been deposited with the Open Funder Registry.

Conflict of interest: None declared.

Copyright CERS 2016 
risk for asthma attacks [16]. But we should not assume all asthma attacks are the same; overwhelming allergen exposure, as in the thunderstorm [17] and soya bean [18] asthma epidemics, may be sufficient to cause an acute deterioration in symptoms with no viral infection at all, and the pathophysiology may be different. So clearly asthma attacks are important and have multiple possible roots, so a single biomarker is unlikely to unlock the prevention of all attacks.

In this issue of the European Respiratory Journal, LEzmi et al. [19] focus on the mast cell in children with severe symptoms. Unfortunately, their definition of "symptomatic" included both poor control and asthma attacks, which may have lumped together two different groups of patients. However, this experienced group did demonstrate that patients who had severe symptomatic asthma did not merely have underlying mucosal eosinophilic airway inflammation, but also that mast cells were potentially important when compared with those asthmatic patients that had few symptoms. They also had a control group of children being investigated for sarcoidosis; as with all paediatric bronchoscopic studies, the ideal control group (truly normal children) could not be studied for obvious ethical reasons. There are some technical limitations, since they quantified mast cells by either Giemsa or c-kit staining. The argument against using a more specific mast cell stain such as tryptase was that extracellular granules would not be detected. However, c-kit is not mast cell specific [20], thus raising the possibility of false positive findings. In addition, specific stains to detect eosinophils, neutrophils or lymphocytes were not used. Within these limitations, there was no overall increase in mast cells between asthmatics and controls, as has been shown in previous paediatric studies [21]. If anything fewer mast cells were present in asthma; but, echoing the findings in adult studies [22], there was an increase in mast cells associated with airway smooth muscle (ASM) in severe asthma. However, when this group was subdivided by the presence or otherwise of symptoms, Giemsa mast cell positivity in ASM was the same, but there was a trend for greater c-kit positivity in those patients experiencing symptoms. Confusingly, submucosal but not ASM c-kit positive mast cells correlated with severe asthma attacks (but not hospitalisations) despite there being a correlation between ASM and submucosal mast cells. The authors speculated that, because c-kit stains intact and degranulated mast cells while Giemsa stains only intact cells, there was more mast cell degranulation in severe asthma.

The authors are to be congratulated on the performance of such a technically challenging study in children. It cannot be overemphasised that paediatricians must do studies in children and not uncritically extrapolate from adult studies. For example, despite the elegant demonstration of a T-helper cell (Th)2 high subgroup in adult asthma [23], two major studies in children have failed to find evidence of Th2 cytokines [21, 24], calling into question whether the anti-interleukin (IL)-5 strategies that have been so successful in preventing asthma attacks in adults will work in children [25]. So this sort of invasive study, gleaning invaluable research insights from the performance of clinical investigations, is essential if progress is to be made.

As always, there are methodological issues. In all severe asthma studies, the gigantic elephant in the room is adherence. In this study adherence was judged by the physicians and the criteria included whether the child could demonstrate that they could use their inhaler. Our experience is that this is clearly inadequate [26]; we need now to move the bar so that adherence cannot be judged adequate unless directly observed or electronically monitored, and all severe asthma clinics need to move to this as part of their assessment. Physician estimate is guesswork, prescription uptake and medication utilisation are far from being the same thing, and so-called validated questionnaires are not worth the paper they are written on [27]. So it is not clear whether these authors are describing two different populations of asthmatics, or merely the differences between asthmatics who do and do not take treatment. Another issue is the use of an oral steroid trial prior to bronchoscopy in only those children that had persistent airflow limitation. Mast cells are relatively steroid sensitive, and thus varying the use of systemic steroids prior to biopsy may have affected the data.

A more general issue is, what is an acute asthma attack, and how many are needed to define "severe asthma"? Conventional definitions include unscheduled healthcare visits, the need for steroid bursts and hospital admission, but these may be misleading. The fact that a child is known to be under the care of a tertiary asthma centre may lead to the severity of an attack being overcalled, particularly late at night with junior paediatricians assessing the child. Indeed, one such child under our care was brought to hospital at midnight with an "asthma attack" and was given intravenous salbutamol. Only with the "retrospectoscope" was it realised that the child had an oxygen saturation of $99 \%$ on room air and the problem was vocal cord dysfunction. Is there a justification for requiring multiple acute attacks to define severe asthma? The authors reasonably enough chose three, on the basis of the current guidelines when they planned the study; the next iteration of the guidelines chose two [28], so they re-analysed their data, without the conclusions changing. However, given the NRAD findings that one severe attack is predictive of another acute attack or death [10], many would believe that a single attack should be enough to be a high-risk marker, even accepting that many people who have an attack survive and avoid future trouble.

What are the practical implications of their findings? It would be naïve to think that treatment of a single cell type will be sufficient to prevent asthma attacks. Indeed it has to be said that mast cell blockers such 
as cromolyns have fallen out of favour because they are very poor asthma preventers. Of course this may be a problem of access to mast cells, if the relevant location is deep in the ASM, well away from the airway lumen. However, mast cell numbers will not be a diagnostic test (too much overlap between groups) or therapeutically relevant unless new treatments can be discovered.

What we really need to do is to progress to noninvasive biomarkers of: risk of attack (so preventive measures can be instituted); onset of an attack (so we are all on the same diagnostic page); and termination of the attack (so we know when to wean off treatment). On all these fronts we have failed to move into the 21st century; the comparison of our crude measurements with the new molecular approaches in CF [29] and tuberculosis [30], for example, is stark, and we are still a long way from this more objective approach being a clinical reality.

Of more current relevance for the clinician is to think of asthma attacks in terms of the recently proposed framework for airways disease [31], namely components of airway pathology, extrapulmonary factors (comorbidities) and environmental and life-style issues. Clearly an asthma attack is a sign of failure of prevention, and a warning shot that there is trouble ahead. Residual airway pathology, certainly including mucosal eosinophilia and probably mast cell myositis should certainly command attention, but at our peril do we make this our sole focus. Given that asthma is a potentially lethal disease, asthma plans and proper use of asthma medications are also important, especially in the age of molecular biology. We should follow the example of the cardiologists: a heart attack is followed by an energetic and focused response to head off future trouble, and the same should be the case for lung attacks. What went wrong? Was the treatment plan followed, in which case should it be modified, or was it neglected, in which case reinforcement is needed. So, in answer to the question we posed in the title, yes, mast cells may be important, but they are only one part of the asthma attack, which is an increasingly complex show in town.

\section{References}

FitzGerald JM. Targeting lung attacks. Thorax 2011; 66: 365-366.

Bush A, Pavord I. Following Nero: fiddle while Rome burns, or is there a better way? Thorax 2011; 66: 367. Sanders DB, Bittner RC, Rosenfeld M, et al. Failure to recover to baseline pulmonary function after cystic fibrosis pulmonary exacerbation. Am J Respir Crit Care Med 2010; 182: 627-632.

4 Sanders DB, Bittner RC, Rosenfeld M, et al. Pulmonary exacerbations are associated with subsequent FEV1 decline in both adults and children with cystic fibrosis. Pediatr Pulmonol 2011; 46: 393-400.

5 de Boer K, Vandemheen KL, Tullis E, et al. Exacerbation frequency and clinical outcomes in adult patients with cystic fibrosis. Thorax 2011; 66: 680-685.

6 Sunther M, Bush A, Hogg C, et al. Recovery of baseline lung function after pulmonary exacerbation in children with primary ciliary dyskinesia. Pediatr Pulmonol 2016; in press [DOI: 10.1002/ppul.23479].

7 Mcllwaine MP, Alarie N, Davidson GF, et al. Long-term multicentre randomised controlled study of high frequency chest wall oscillation versus positive expiratory pressure mask in cystic fibrosis. Thorax 2013; 68: 746-751.

8 Valery PC, Morris PS, Byrnes CA, et al. Long-term azithromycin for Indigenous children with non-cystic-fibrosis bronchiectasis or chronic suppurative lung disease (Bronchiectasis Intervention Study): a multicentre, double-blind, randomised controlled trial. Lancet Respir Med 2013; 1: 610-620.

9 Main E. Airway clearance research in CF: the 'perfect storm' of strong preference and effortful participation in long-term, non-blinded studies. Thorax 2013; 68: 701-702.

10 Royal College of Physicians, National Review of Asthma Deaths. Why asthma still kills. www.rcplondon.ac.uk/ projects/outputs/why-asthma-still-kills Date last updated: August 11, 2015.

11 Reddel H, Ware S, Marks G, et al. Differences between asthma exacerbations and poor asthma control. Lancet 1999; 353: 364-369.

12 Belgrave DC, Buchan I, Bishop C, et al. Trajectories of lung function during childhood. Am J Respir Crit Care Med 2014; 189: 1101-1109.

13 O'Byrne PM, Pedersen S, Lamm CJ, et al. Severe exacerbations and decline in lung function in asthma. Am J Respir Crit Care Med 2009; 179: 19-24.

$14 \mathrm{Xu} \mathrm{M}$, Tantisira KG, Wu A, et al. Genome Wide Association Study to predict severe asthma exacerbations in children using random forests classifiers. BMC Med Genet 2011; 12: 90.

15 Murray CS, Poletti G, Kebadze T, et al. Study of modifiable risk factors for asthma exacerbations: virus infection and allergen exposure increase the risk of asthma hospital admissions in children. Thorax 2006; 61: 376-382.

16 Haldar P, Pavord ID, Shaw DE, et al. Cluster analysis and clinical asthma phenotypes. Am J Respir Crit Care Med 2008; 178: 218-224.

17 Newson R, Strachan D, Archibald E, et al. Effect of thunderstorms and airborne grass pollen on the incidence of acute asthma in England, 1990-94. Thorax 1997; 52: 680-685.

18 Ballester F, Soriano JB, Otero I, et al. Asthma visits to emergency rooms and soybean unloading in the harbors of Valencia and A Coruña, Spain. Am J Epidemiol 1999; 149: 315-322.

19 Lezmi G, Galmiche-Rolland L, Rioux S, et al. Mast cells are associated with exacerbations and eosinophilia in children with severe asthma. Eur Respir J 2016; 48: 1320-1328.

20 Krishnamoorthy N, Oriss TB, Paglia M, et al. Activation of c-Kit in dendritic cells regulates $\mathrm{T}$ helper cell differentiation and allergic asthma. Nat Med 2008; 14: 565-573.

21 Bossley C, Fleming L, Gupta A, et al. Pediatric severe asthma is characterized by eosinophilia and remodeling without $\mathrm{T}_{\mathrm{H}} 2$ cytokines. J Allergy Clin Immunol 2012; 129: 974-982.

22 Brightling CE, Bradding P, Symon FA, et al. Mast-cell infiltration of airway smooth muscle in asthma. N Engl J Med 2002; 346: 1699-1705. 
23 Woodruff PG, Modrek B, Choy DF, et al. T-helper type 2-driven inflammation defines major subphenotypes of asthma. Am J Respir Crit Care Med 2009; 180: 388-395.

24 Fitzpatrick AM, Higgins M, Holguin F, et al. The molecular phenotype of severe asthma in children. J Allergy Clin Immunol 2010; 125: 851-857.

25 Pavord ID, Korn S, Howarth P, et al. Mepolizumab for severe eosinophilic asthma (DREAM): a multicentre, double-blind, placebo-controlled trial. Lancet 2012; 380: 651-659.

26 Bracken MB, Fleming L, Hall P, et al. The importance of nurse-led home visits in the assessment of children with problematic asthma. Arch Dis Childs 2009; 94: 780-784.

27 Nagakumar P, Hall P, Saglani S, et al. P55 Is prescription uptake and medication adherence rating scale (MARS) a useful tool in assessing asthma control in children with problematic severe asthma (PSA)? Thorax 2014; 69: Suppl 2, A98.

28 Chung KF, Wenzel SE, Brozek JL, et al. International ERS/ATS guidelines on definition, evaluation and treatment of severe asthma. Eur Respir J 2014; 43: 343-373.

29 Nick JA, Sanders LA, Ickes B, et al. Blood mRNA biomarkers for detection of treatment response in acute pulmonary exacerbations of cystic fibrosis. Thorax 2013; 68: 929-937.

30 Anderson ST, Kaforou M, Brent AJ, et al. Diagnosis of childhood tuberculosis and host RNA expression in Africa. N Engl J Med 2014; 370: 1712-1723.

31 Agusti A, Bel E, Thomas $\mathrm{M}$, et al. Treatable traits: toward precision medicine of chronic airway diseases. Eur Respir J 2016; 47: 410-419. 